\title{
Legal case-based reasoning as practical reasoning
}

\author{
KATIE ATKINSON and TREVOR BENCH-CAPON \\ Department of Computer Science, University of Liverpool, Liverpool, L69 3BX, UK \\ E-mail:katie@csc.liv.ac.uk
}

\begin{abstract}
In this paper we apply a general account of practical reasoning to arguing about legal cases. In particular, we provide a reconstruction of the reasoning of the majority and dissenting opinions for a particular well-known case from property law. This is done through the use of Belief-Desire-Intention (BDI) agents to replicate the contrasting views involved in the actual decision. This reconstruction suggests that the reasoning involved can be separated into three distinct levels: factual and normative levels and a level connecting the two, with conclusions at one level forming premises at the next. We begin by summarising our general approach, which uses instantiations of an argumentation scheme to provide presumptive justifications for actions, and critical questions to identify arguments which attack these justifications. These arguments and attacks are organised into argumentation frameworks to identify the status of individual arguments. We then discuss the levels of reasoning that occur in this reconstruction and the properties and significance of each of these levels. We illustrate the different levels with short examples and also include a discussion of the role of precedents within these levels of reasoning.
\end{abstract}

Key words: argumentation, case based reasoning, intermediate legal concepts, legal decision making, practical reasoning, teleological reasoning

\section{Introduction}

One of the first projects in AI and Law, the TAXMAN project (McCarty and Sridharan 1982) of McCarty and Sridharan (most recently reported in McCarty (1995)) had as its goal providing a computational means of generating the majority and minority opinions in a celebrated tax law case, Eisner v. Macomber, 252 U.S. 189 (1920). The work described in this paper is in that tradition: here we will present a computational means of simulating the opinion and dissent in perhaps the most famous case in property law, Pierson v. Post, 3 Cai R 1752 Am Dec 264 (Supreme Court of New York, 1805), said to have been read by (or at least assigned to) every law student in America. We will also consider some further arguments of the debate that have arisen in subsequent commentary and discussion.

In addition to the computational reconstruction of this particular case, we will also discuss how the reasoning involved can be separated into three 
distinct layers. We will explore these layers in more detail, together with consideration of how precedents are treated. For this, we will use two running examples: the law relating to UK Sickness Benefit, as stated in the Social Security Act 1975 (and which was current until 1995 when the system was radically reformed), and US Trades Secrets Law, as described in the Restatement of Torts. Both of these have been the subject of investigation in AI and Law. The first is an example of the kind of area in which rule-based expert systems of the 1980s and 1990s operated, and is discussed in BenchCapon (1991a) ${ }^{1}$. The second has been the subject of investigation in connection with case-based approaches, e.g. Ashley (1990). These two examples provide some instructive differences.

Our approach is to reconstruct legal cases using Belief-Desire-Intention (BDI) agents to represent different perspectives on the case and builds on work we have developed relating to debates concerning practical reasoning - reasoning about what should be done. In Greenwood et al. (2003) we argued that reasoning about legal cases should be seen as a species of practical reasoning, and proposed an argument scheme for practical reasoning. Instantiating this argument scheme provides a presumptive justification for an action (here: deciding a legal case), and that paper also identified the ways in which this presumption could be challenged. The argument scheme can be seen as a refinement of the sufficient condition scheme for practical reasoning proposed in Walton (1996), and the attacks on arguments of this form can be construed in terms of critical questions directed against the argument (Atkinson et al. 2004b). To make the process of practical reasoning computational, we have provided definitions and pre-conditions for instantiating the scheme and challenging instantiations of the scheme for use in multi-agent systems based on the BDI model (Atkinson et al. 2004a). The presumptive arguments and attacks on them are resolved through organisation into a value-based argumentation framework (VAF) (Bench-Capon 2003a), enabling the calculation of the dialectical status of the various arguments, with respect to the participants in the debate. This technique has also been applied in a political application (Atkinson et al. 2005a) and a medical application (Atkinson et al. 2005b). The key points of this work will be recapitulated in Section 2. Our approach will be to model the various participants in the debate as different agents. We see the disagreements as grounded in divergent beliefs, goals and values, and therefore will use different agents to represent the different views that can be brought to bear on the problem. Section 3 will describe the case and the agents we will use. In Section 4 we will represent the beliefs, desires and values of the four agents pertinent to the problem and generate the arguments that these agents can form on the basis of this knowledge, and show the relations between these arguments as a set of VAFs. In Section 5 we will relate this to the opinions in the original 
decision. Section 6 explores in more detail the different levels of reasoning that emerged from the reconstruction of the Person v. Post case. Section 7 offers a discussion of the different modes of agreement and disagreement that can occur at each of the different levels. Section 8 examines how precedents relate to these levels of reasoning through the use of two examples. Section 9 discusses the structuring of cases through the separation of the issues involved. In Section 10 we give a brief discussion of how the work presented in this paper relates to a number of other areas from AI and Law. Finally, Section 11 offers some concluding remarks.

The main contribution of this paper is to bring together our earlier work so as to provide a thoroughly worked out example of the application of this approach to law and to show how this has given us insight into the different types of reasoning involved in legal cases.

\section{General approach to practical reasoning with agents}

Our starting point is to see deciding a case as an action to be justified, rather than the recognition of a property of a case which enables it to be classified. Our theory has its roots in the idea that practical reasoning is a species of presumptive reasoning, and builds on the work of Walton (1996). His account views presumptive reasoning as the instantiation of an argument scheme which is then subject to critique through a number of characteristic critical questions associated with that particular scheme. Walton (1996) gives 25 argument schemes: we have taken one of them, the sufficient condition scheme for practical reasoning, and refined it by unpacking his notion of a goal into three elements: the state of affairs brought about by the action, the goal (the desired features in that state of affairs) and the value (the reason why those features are desirable). These fine grained distinctions enable us to extend the range of critical questions that can be posed against this scheme. We base reasoning about legal decisions on our extended argument scheme, which is expressed as follows:

\section{AS1:}

In the current circumstances $R$

We should perform action A

To bring about new circumstances $\mathrm{S}$

Which will realise goal $\mathrm{G}$

And promote value $\mathrm{V}$

As applied to a legal case the action is to decide for, say the plaintiff, resulting in the facts and a decision for the plaintiff. The idea is that deciding for the plaintiff when particular facts hold advances some desirable purpose. We can restate AS1 as:

Given the facts of this case (R) 
we should decide for the plaintiff (A)

as a decision for the plaintiff when some subset of $R(G)$

will promote some value $(\mathrm{V})$

This presumptive justification may be attacked in a large variety of ways, as described in Greenwood et al. (2003), as the various elements and the connections between them are open to question, and additionally there may be alternative possible actions, and side effects of the proposed action. We will define the attacks used in this paper in Section 2.1.

The computational setting for our approach is a multi-agent system, in which the agents form intentions based on their beliefs and desires. This is essentially the standard BDI agent model (Wooldridge 2000), except that we make a small extension by associating each desire with a value, the reason why it is desirable.

We begin by stating the definitions for our general theory. The definitions that follow describe how an agent can put forward a position regarding the justification of an action, in accordance with our theory. These definitions are not intended to be prescriptive of any internal representation of the agents' beliefs, plans and goals. It is assumed that an agent using the definitions provided below would be equipped with some suitable internal representation for these elements. The formalism presented here is intended as a way in which agents' beliefs can be expressed independently of their internal representation in order to describe how argument scheme AS1, and attacks upon it, can be instantiated.

\subsection{DEFINITIONS}

DEFINITION 1 The Beliefs of an Agent. The beliefs of an agent $j$ is a four tuple $\left\langle\mathrm{W}_{j}, \mathrm{~A}_{j}, \mathrm{D}_{j}, \mathrm{~V}_{j}\right\rangle$ where,

$\mathrm{W}_{j}$ represents beliefs of agent $j$ about the world;

$\mathrm{A}_{j}$ represents beliefs of agent $j$ about actions;

$\mathrm{D}_{j}$ represents beliefs about the desires of agent $j$;

$\mathrm{V}_{j}$ represents beliefs about the values of agent $j$

DEFINITION 2 Beliefs about the World. The beliefs of an agent are used to determine which pre-conditions of plans in the agent's plan library ${ }^{2}$ are satisfied.

The beliefs about the world of agent $j$ are a set of assignments of truth values to propositions about the world.

Let $\mathrm{M}$ denote the set of all agents in the system. Let $\mathrm{P}$ denote the set of all propositions such that a proposition $p \in \mathrm{W}_{j}$ for some agent $j \in \mathrm{M}$.

DEFINITION 3 Beliefs about Actions. The actions available to an agent consist of plans from the agent's plan library which are composed of one or more actions. 
The beliefs about action of agent $j$ are a set of triples $\left\langle\alpha, \operatorname{Pre}_{\alpha j}, \operatorname{Post}_{\alpha j}\right\rangle$ where, $\operatorname{Pre}_{\alpha j}$ and $\operatorname{Post}_{\alpha j}$ are assignments to propositions.

$\mathrm{W}_{j \alpha}$ is the state of the world that $j$ believes will result from performing $\alpha$.

Additionally, $j$ may assume that $\alpha$ can be performed if all elements of $\operatorname{Pre}_{\alpha j}$ can be assumed to be satisfied with respect to $\mathrm{W}_{j}$.

The set $\mathrm{A}$ denotes the set of all actions such that $\left\langle\alpha, \operatorname{Pre}_{\alpha j}, \operatorname{Post}_{\alpha j}\right\rangle \in \mathrm{A}_{j}$ for some agent $j \in \mathrm{M}$.

DEFINITION 4 Desires of an Agent. The desires of an agent are the post-conditions of plans from the agent's plan library.

The desires of an agent $j$ are a set of pairs $\left\langle d, \operatorname{Cond}_{d j}\right\rangle$ such that,

$d$ is a desire and Cond $d j$ is an assignment to a proposition p. The interpretation is that $j$ believes that the desire $d$ is satisfied if $\operatorname{Cond}_{d j}$ is satisfied with respect to $\mathrm{W}_{j}$. The notions of satisfaction and assumed satisfaction for Cond $_{d j}$ are the same as that for $\operatorname{Pre}_{\alpha j}$.

The set $\mathrm{D}$ denotes the set of all desires such that $\left\langle d, \operatorname{Cond}_{d j}\right\rangle \in \mathrm{D}_{j}$ for some agent $j \in \mathrm{M}$.

DEFINITION 5 Values of an Agent. The values of an agent are associated with desires and they give the reasons as to why the agent wants to achieve a particular desire.

The values of an agent $j$ is a set of triples $\left\langle v, d, \operatorname{prom}_{v j}\right\rangle$ such that, $v$ is a value, $d$ is a desire, and $\operatorname{prom}_{v j}$ is the promotion of the value.

Following the definitions from Section 3.2, it is assumed that a value may be:

(i) promoted through fulfilment of a desire, represented by a positive number,

(ii) demoted through the fulfilment of a desire, represented by a negative number, or

(iii) neither promoted nor demoted (i.e. neutral) through fulfilment of the desire, represented by 0 .

The set $\mathrm{V}$ denotes the set of all values such that $\left\langle v, d, \operatorname{prom}_{v j}\right\rangle \in \mathrm{V}_{j}$ for some agent $j \in \mathrm{M}$.

\section{DEFINITION 6 Notions of Satisfaction of Formulae.}

The agent's full set of beliefs is represented as a well-formed formula of standard propositional logic, in which all the propositions are given a truth value by the agent.

Let satA (Formula, $\mathrm{W}_{j}$ ) be true if Formula can be assumed to be satisfied with respect to $\mathrm{W}_{j}$. A Formula can be assumed to be satisfied if it is not believed to be false. 
For example, if agent $j$ holds the belief that proposition $p$ is true, proposition $q$ is false and proposition $r$ is unknown, e.g. $\mathrm{W}_{j}=\{(p, \mathrm{~T}),(q, \mathrm{~F})$, $(r, \mathrm{U})\}$, then he can assume that the formula $\{p \& r\}$ is satisfied.

Let satS (Formula, $\mathrm{W}_{j}$ ) be true if Formula can be satisfied with respect to $\mathrm{W}_{j}$. A Formula is satisfied if it is believed to be true.

For example, if agent $j$ holds the same beliefs as above, then he can state that the formula $\{p\}$ is satisfied, as this is the only proposition known to be true and $\{p \& r\}$ cannot be satisfied.

This allows us to distinguish between the mere assumption that pre-conditions hold and the actual knowledge that they hold. This reflects the fact that agents often need to make assumptions because knowledge is typically incomplete.

Now $j$ has a presumptive argument for $\alpha$ if:

there is an $\left\langle\alpha, \operatorname{Pre}_{\alpha j}, \operatorname{Post}_{\alpha j}\right\rangle \in \mathrm{A}_{j}$ such that:

$\operatorname{sat} \mathrm{A}\left(\operatorname{Pre}_{a j}, \mathrm{~W}_{j}\right)$;

$\operatorname{sat} \mathrm{A}\left(\mathrm{Cond}_{d j}, \mathrm{~W} j\right)$ follows the execution of $\alpha$ and

$\operatorname{sat} \mathrm{A}\left(\operatorname{Cond}_{d j}, \mathrm{~W}_{j} \alpha\right)$ and

there is a $\left\langle v, d, \operatorname{prom}_{v j}\right\rangle$, such that $\operatorname{prom}_{v j}>0$.

The position is expressed as:

In circumstances $r$, where each $r \in \mathrm{R}$ is the first term in each element of $\operatorname{Pre}_{\alpha j}$,

Performing $\alpha$,

Will result in $s$, where each $s \in \mathrm{S}$ is the first term in each element of Post ${ }_{a j}$,

Which will realise $d$,

Which promotes $v$.

On the basis of these definitions we can state the following preconditions for attacking such presumptive arguments. Each of these attacks may be associated with a critical question, as described in Atkinson et al. (2004b). For each attack we give the critical question from which it derives and a natural language expression of the attack. The complete set of pre-conditions for attacks is in Atkinson et al. (2004a): here we give only those used subsequently in the paper.

The definitions for the attacks are as follows:

There is an attacking agent $k \in \mathrm{M}$ such that $\left\langle\mathrm{W}_{k}, \mathrm{~A}_{k}, \mathrm{D}_{k}, \mathrm{~V}_{k}\right\rangle$ and agent $k$ may attack the position put forward by agent $j$ using the set of attacks subject to the following conditions:

Source CQ: Are the believed circumstances true? (CQ1).

Attack 1a: Pre-conditions for agent $k$ to make an attack: $\operatorname{satA}\left(\operatorname{Pre}_{\alpha k}, \mathrm{~W}_{k}\right)$ and, not satS(Pre $\left.\operatorname{Po}_{\alpha k}, \mathrm{~W}_{k}\right)$.

Argument: $p$ may not be true. 
Source CQ: Assuming the circumstances are true, does the action have the stated consequences? (CQ2).

Attack 2a: Pre-conditions for agent $k$ to make an attack: $\operatorname{sat} \mathrm{A}\left(\mathrm{W}_{j \alpha}, \mathrm{W}_{k \alpha}\right)$ and, not satS $\left(\mathrm{W}_{j \alpha}, \mathrm{W}_{k \alpha}\right)$.

Argument: $\alpha$ may not have the desired consequences.

Source CQ: Does the goal realise the value intended? (CQ4).

Attack 4a: Pre-conditions for agent $k$ to make an attack: $\left\langle v, d, \operatorname{prom}_{v k}\right\rangle$ and, $\operatorname{prom}_{v k} \leq 0$.

Argument: the desire may not promote the value.

Attack 4b: Pre-conditions for agent $k$ to make an attack: $\left\langle v, d, \operatorname{prom}_{v k}\right\rangle$ and, $\operatorname{prom}_{v k}<0$.

Argument: the desire will not promote the value.

Source CQ: Are there alternative ways of realising the same goal? (CQ6).

Attack 6: Pre-conditions for agent $k$ to make an attack: $\operatorname{satA}\left(\operatorname{Pre}_{\beta k}, \mathrm{~W}_{k}\right)$ and, $\operatorname{sat} \mathrm{A}\left(\operatorname{Cond}_{d k}, \mathrm{~W}_{k \beta}\right)$ and $\beta \neq \alpha$.

Argument: there is an alternative action $\beta$ which will realise the same desire.

Source CQ: Are there alternative ways of promoting the same value? (CQ7).

Attack 7a: Pre-conditions for agent $k$ to make an attack: satA $\left(\operatorname{Pre}_{\beta k}, \mathrm{~W}_{k}\right)$ and, for some $e, e \neq d$, satA $\left(\operatorname{Cond}_{e k}, \mathrm{~W}_{k} \beta\right)$ and $\beta \neq \alpha$ and,$\left\langle v, e, \operatorname{prom}_{v k}\right\rangle$ and, $\operatorname{prom}_{v k}>0$.

Argument: there is an alternative action $\beta$, leading to satisfaction of an alternative desire, which will promote the value.

Attack 7b: Pre-conditions for agent $k$ to make an attack: $\operatorname{sat} \mathrm{A}\left(\operatorname{Cond}_{e k}, \mathrm{~W}_{k \alpha}\right), e \neq d$ and, $\left\langle v, e, \operatorname{prom}_{v k}\right\rangle$ and, $\operatorname{prom}_{v k}>0$.

Argument: $\alpha$ has a side effect which satisfies an alternative desire, which promotes the value.

Source CQ: Does doing the action have a side effect which demotes the value V? (CQ8).

Attack 8: Pre-conditions for agent $k$ to make an attack: satA $\left(\operatorname{Cond}_{e k}, \mathrm{~W}_{k \alpha}\right), e \neq d$ and,

$\left\langle v, e, \operatorname{prom}_{v k}\right\rangle$ and, $\operatorname{prom}_{v k}<0$. 
Argument: $\alpha$ has a side effect which satisfies an alternative desire, which demotes the value.

Source CQ: Would doing the action promote some other value? (CQ10).

Attack 10: Pre-conditions for agent $k$ to make an attack: $\operatorname{sat} \mathrm{A}\left(\operatorname{Cond}_{e k}, \mathrm{~W}_{k \alpha}\right), e \neq d$ and, there is a $w, w \neq v$ such that $\left\langle w, e, \operatorname{prom}_{w k}\right\rangle$ and, $\operatorname{prom}_{w k}>0$.

Argument: $\alpha$ has a side effect which satisfies an alternative desire, which promotes some other value.

Source CQ: Does doing the action preclude some other action which would promote some other value? (CQ11).

Attack 11a: Pre-conditions for agent $k$ to make an attack:

$\operatorname{satA}\left(\operatorname{Pre}_{\alpha k}, \mathrm{~W}_{k}\right)$ and,

$\operatorname{sat} \mathrm{A}\left(\operatorname{Cond}_{e k}, \mathrm{~W}_{k \beta}\right), e \neq d$ and,

there is a $w, w \neq v$ such that $\left\langle w, e, \operatorname{prom}_{w k}\right\rangle$ and,

$\operatorname{prom}_{w k}>0$ and,

not $\operatorname{sat} \mathrm{A}\left(\operatorname{Pre}_{\alpha k}, \mathrm{~W}_{k \beta}\right)$ and,

not satA( $\left.\operatorname{Pre}_{\beta k}, \mathrm{~W}_{k \alpha}\right)$.

Argument: doing $\alpha$ precludes some other action which would promote some other value.

Source CQ: Are the particular aspects of $\mathrm{S}$ represented by $\mathrm{G}$ possible? (CQ15).

Attack 15: Pre-conditions for agent $k$ to make an attack:

$\left\langle d, \operatorname{Cond}_{d k}\right\rangle \notin \mathrm{D}_{k}$.

Argument: $d$ is not a meaningful desire for the attacking agent.

Source CQ: Is the value proposed indeed a legitimate value? (CQ16).

Attack 16: Pre-conditions for agent $k$ to make an attack: $\left\langle v, d, \operatorname{prom}_{v k}\right\rangle \notin \mathrm{V}_{k}$.

Argument: $v$ is not a recognised value.

Now given a set of agents and a situation in which an action must be chosen we can first instantiate a number of presumptive justifications for each agent, and then see which attacks the agents can make on these justifications. The result will be a set of arguments and a set of attack relations between them, providing the key elements for an argumentation framework (Dung 1995). Moreover, since the arguments produced by instantiating AS1 are associated with values, we can see this as a VAF (Bench-Capon 2003a), and use the procedures in that paper to calculate the dialectical status of the arguments with respect to the different audiences represented by the different agents.

This process will be illustrated by a detailed exploration of our example case in Section 4. 


\section{Representing our case}

We begin by giving a summary of the decision in Pierson v. Post. ${ }^{3}$ The language used is appealingly extravagant and may in part account for the popularity of the case in teaching. It begins with a statement of the facts. After giving the procedural context the facts are stated as:

Post, being in possession of certain dogs and hounds under his command, did, upon a certain wild and uninhabited, unpossessed and waste land, called the beach, find and start one of those noxious beasts called a fox, and whilst there hunting, chasing and pursuing the same with his dogs and hounds, and when in view thereof, Pierson, well knowing the fox was so hunted and pursued, did, in the sight of Post, to prevent his catching the same, kill and carry it off. A verdict having been rendered for the plaintiff below, the defendant there sued out a certiorari and now assigned for error, that the declaration and the matters therein contained were not sufficient in law to maintain an action.

The opinion of the court was delivered by Tompkins, J. The decision can be seen as a sequences of parts, to which we will give identifying numbers Tn for later reference. He begins by stating the question to be determined (T1):

The question submitted by the counsel in this cause for our determination is, whether Lodowick Post, by the pursuit with his hounds in the manner alleged in his declaration, acquired such a right to, or property in, the fox, as will sustain an action against Pierson for killing and taking him away?

The next paragraph (T2) discusses a number of authorities on the question of whether a wild animal can be owned other than through bodily possession, or at least mortal wounding. Tompkins concludes:

The foregoing authorities are decisive to show that mere pursuit gave Post no legal right to the fox, but that he became the property of Pierson, who intercepted and killed him.

He then (T3) dismisses a number of previous, mostly English, cases as irrelevant because they:

... have either been discussed and decided upon the principles of their positive statute regulations, or have arisen between the huntsman and the owner of the land upon which beasts ferae naturae have been apprehended ... 
He next returns to his authorities (T4), and whilst being inclined to accept that wounding would constitute possession, states:

The case now under consideration is one of mere pursuit, and presents no circumstances or acts which can bright it within the definition of occupancy by Puffendorf, or Grotius, or the ideas of Barbeyrac upon that subject.

Next (T5) he considers a precedent case, Keeble v. Hickergill, 11 East 574, 103 Eng Rep 1127 (Queen's Bench, 1707). This case had been cited as an example of where malicious interference in hunting was deemed to provide a reason for remedy. Tompkins distinguished this both on the grounds that Keeble suffered economic loss, and that the animals were on his own land:

...the action was for maliciously hindering and disturbing the plaintiff in the exercise and enjoyment of a private franchise; in the report of the same case, (3 Salk. 9) Holt, Ch. J., states, that the ducks were in the plaintiff's decoy pond, and so in his possession, from which it is obvious the court laid much stress in their opinion upon the plaintiff's possession of the ducks, ratione soli.

He then (T6) motivates his decision by a desire that the law should be clear:

We are the more readily inclined to confine possession or occupancy of beasts ferae naturae, within the limits prescribed by the learned authors above cited, for the sake of certainty, and preserving peace and order in society. If the first seeing, starting, or pursuing such animals, without having so wounded, circumvented or ensnared them, so as to deprive them of their natural liberty, and subject them to the control of their pursuer, should afford the basis of actions against others for intercepting and killing them, it would prove a fertile source of quarrels and litigation.

Finally (T7) he concludes by saying that even if any malice was involved this "act was productive of no injury or damage from which a legal remedy can be applied", suggesting that such damage needs to be economic to provide any remedy: the law cannot compensate for loss of sport.

The overall thrust of this decision seems to be that the law is rather clear as it stands: the only question is ownership, and that ownership in a wild animal cannot be acquired through mere pursuit. Moreover, where there is no measurable damage, no legal remedy is appropriate.

Livingston, J. then gives his dissent. Again,we number its parts Ln for later reference. $\mathrm{He}(\mathrm{L} 1)$ agrees that there is a single question: whether pursuit 
of the fox gave "such an interest in the animal, as to have a right of action against another". He then says (L2) that such cases should not be brought to court but arbitrated by sportsmen (ignoring the bias in favour of Post that such a tribunal would have). He then (L3) argues that hunting should be encouraged as the depredation of foxes "on farmers and on barn yards have not been forgotten; and to put him to death wherever found, is allowed to be meritorious, and of public benefit" and that no one would hunt if their sport were regularly spoiled by interventions such as that of Pierson. He says (L4) the authorities cited are old, and that the court is able to state a new law: "if men themselves change with the times, why should not laws also undergo an alteration?" In any event the authorities do not require bodily possession and so a finding for Post would be compatible with them. The crux of his argument (L5) is that

... the interest of our husbandmen, the most useful of men in any community, will be advanced by the destruction of a beast so pernicious and incorrigible, we cannot greatly err, in saying, that a pursuit like the present, through waste and unoccupied lands, and which must inevitably and speedily have terminated in corporal possession, or bodily seisin, confers such a right to the object of it, as to make any one a wrongdoer, who shall interfere and shoulder the spoil.

In sum: since fox hunting is of public benefit because it assists farmers it should be encouraged by giving the sportsman protection of the law.

The arguments of Tompkins and Livingston are couched in very different terms. Whereas Tompkins confines himself to discussion in terms of legal concepts - which to him clearly provide no basis for remedy, Livingston talks mainly about the real world, and whether fox hunting is desirable or not, and argues that if it is, the legal concepts should be interpreted so as to provide a remedy.

In our reconstruction of the arguments we will use two different agents to represent Tompkins and Livingston. We will refer to these agents as $\mathrm{T}$ and $\mathrm{L}$, respectively. We will also use two additional agents to make points not raised in the decision, but which have emerged in subsequent debate.

The first disputes Livingston's claims about the benefit of hunting. Those familiar with the novels of Anthony Trollope will know that fox hunting features quite prominently. In one of his novels, The American Senator (Trollope 1986), a major sub-plot concerns a farmer who poisons a fox. This outrages the hunting community, since they wish to preserve foxes for their sport. It is quite clear that Trollope, who is a fervent pro-hunter, recognises that but for hunting, foxes would be rapidly eliminated by farmers through the more efficient pest control methods of snaring, poisoning, gassing and shooting. If we agree with Livingston that it is "meritorious" and "of public 
benefit" to "put [a fox] to death wherever found", then hunting should be discouraged, since where hunting is encouraged these more efficient methods are subject to social stigma. Trollope, however, does wish to encourage hunting on its intrinsic merits: he would therefore wish the law to condemn Pierson's malicious interference in the sport. We shall call this agent A, for Anthony.

The final agent also disputes whether hunting should be encouraged. A recent Act of Parliament means that fox hunting in the traditional manner will soon be illegal in the UK. The argument here has been solely based on the cruelty of hunting: shooting and gassing are preferred on grounds of humaneness rather than efficiency. On such a view Pierson is acting in a laudable manner, by saving the fox pain, and it is the actions that discourage hunting that should be encouraged. We will call this agent B, after Tony Banks, MP, who was a vocal opponent of hunting during this debate.

In the next section we will instantiate these four agents with the appropriate beliefs, desires and values, in accordance with the definitions given in Section 2.

\section{Generating the arguments}

We begin by identifying desires and values. From Definition 4 we need to identify a set of desires for the agents, and give conditions under which the agents will accept that these desires are realised. Definition 5 requires us to associate these desires with a value, and a degree to which the satisfaction of the desire promotes the value. Tables I and II list the set of desires, conditions, values and degrees that we will use. Since we do not consider varying degrees of promotion we only use 1 where the value is promoted and -1 where it is demoted. Table I gives the initial desires and Table II those that may be derived in the course of the debate. So for example, the desire for "clear law" is satisfied either if we decide for the plaintiff when ownership is established, or we decide for the defendant when no ownership can be established. Similarly, restricted trade requires a decision for the defendant, malicious intent to be found and for the plaintiff to be engaged in economic activity.

There are four agents in the situation: Livingston (L), Tomkins (T), Tony Banks (B) and Anthony Trollope (A). Each agent has different desires they wish to achieve and has different values they wish to promote, though many of these will be in common. From Table I all agents ascribe to desires 1 and 2 and 3. Agents T, L and A do not accept desires 8 and 9 as they do not regard ,reducing animal suffering' as promoting ,humaneness', animal suffering not 
Table I. Possible desires and values in the initial situation

\begin{tabular}{|c|c|c|c|}
\hline No. & Desire & Value affected & Condition to be satisfied \\
\hline 1 & Clear law promotes & Less litigation & $\begin{array}{l}\text { Ownership, Plaintiff } \\
\text { or } \\
\text { No ownership, Defendant } \\
\text { or } \\
\text { No ownership, No possession }\end{array}$ \\
\hline 2 & Unclear law demotes & Less litigation & $\begin{array}{l}\text { Ownership, No possession. } \\
\text { or } \\
\text { No ownership, Plaintiff } \\
\text { or } \\
\text { No ownership, Possession }\end{array}$ \\
\hline 3 & Trade restricted demotes & $\begin{array}{l}\text { Economic } \\
\text { benefit }\end{array}$ & $\begin{array}{l}\text { Malicious intent, Productive } \\
\text { activity, Defendant }\end{array}$ \\
\hline 4 & Malice condemned promotes & Public benefit & Malicious intent, Plaintiff \\
\hline 5 & Malice condoned demotes & Public benefit & Malicious intent, Defendant \\
\hline 6 & $\begin{array}{l}\text { Less threat to } \\
\text { others promotes }\end{array}$ & Public benefit & $\begin{array}{l}\text { Fewer foxes, } \\
\text { Farmers protected }\end{array}$ \\
\hline 7 & $\begin{array}{l}\text { More threat to others } \\
\text { demotes }\end{array}$ & Public benefit & $\begin{array}{l}\neg \text { Fewer foxes, } \\
\neg \text { Farmers protected }\end{array}$ \\
\hline 8 & More suffering demotes & Humaneness & $\neg$ Reduced animal suffering \\
\hline 9 & Less suffering promotes & Humaneness & Reduced animal suffering \\
\hline
\end{tabular}

Table II. Derivable desires and values

\begin{tabular}{llll}
\hline No. & Desire & Value & Condition to be satisfied \\
\hline 10 & Hunting encouraged promotes & Public benefit & Ownership, Pursuit \\
11 & Hunting discouraged promotes & Humaneness & $\neg$ Pursuit, No ownership \\
\hline
\end{tabular}

being a consideration in their pre-animal rights way of thinking. Additionally, agent $\mathrm{T}$ does not accept desires 4-7 as he does not regard ,public benefit' as a value which the law should recognise. The agents may also adopt the derived desires in the course of their reasoning.

We use seven propositions about the world to describe the given situation and these are as follows:

- F1: Post was in pursuit of the fox.

- F2: Post had neither captured nor wounded the fox (he had no possession of the fox). 
Table III. Propositions about the world

\begin{tabular}{lllrlrrr}
\hline Agent & F1 & F2 & F3 & F4 & F5 & F6 & F7 \\
\hline L & 1 & 1 & 0 & 1 & 1 & 1 & 0 \\
T & 1 & 1 & 1 & 1 & 0 & 1 & 0 \\
B & 1 & 1 & -1 & 0 & 0 & 0 & 1 \\
A & 1 & 1 & 1 & 1 & -1 & -1 & 0 \\
\hline
\end{tabular}

- F3: Pierson killed the fox to spoil Post's sport (Pierson had malicious intent).

- F4: Foxes kill livestock.

- F5: Encouraging hunting will reduce the number of foxes.

- F6: Reducing the number of foxes protects the livestock of farmers.

- F7: If hunting is discouraged, needless animal suffering is not inflicted.

Our agents differ quite widely as to the facts. Each agent ascribes to these propositions as shown in Table III with 1 representing belief in the proposition, -1 representing disbelief in the proposition and 0 representing unknown to show that the agent has subscribed to neither belief nor disbelief in the proposition.

Based upon the beliefs and desires given in the above tables, each agent can provide one or more instantiation of AS1. The figures presented below give three argumentation frameworks to show the views of the agents at three different levels: the level of facts about the world, at which new desires can be derived; the level at which the legal system connects with the world to achieve these desires, and at the level of pure legal concepts. These levels are familiar from other work in AI and Law, and are explicit in the functional ontology of Valente (1995), and some discussions of expert systems within the logic programming paradigm, such as Bench-Capon (1991a). Conclusions at lower levels will be used as premises at higher levels. These levels of reasoning will be discussed in more detail in Section 6 onwards, subsequent to the reconstruction of the case. We present each of the argumentation frameworks followed by the instantiations of AS1 and any attacks that can be made on these instantiations using the pre-conditions in Section 2. In the figures, nodes represent arguments. They are labelled with an identifier, the associated value, if any ${ }^{4}$, and on the right hand side, the agent(s) introducing the argument. Arcs are labelled with the number of the attack they represent. We then summarise what can be deduced from the framework in order to proceed to the next level in the argument.

Below is the argumentation framework for Level 1 schemes:

This argumentation framework is constructed from the following arguments. The expression of case-based arguments in terms of AS1 was 


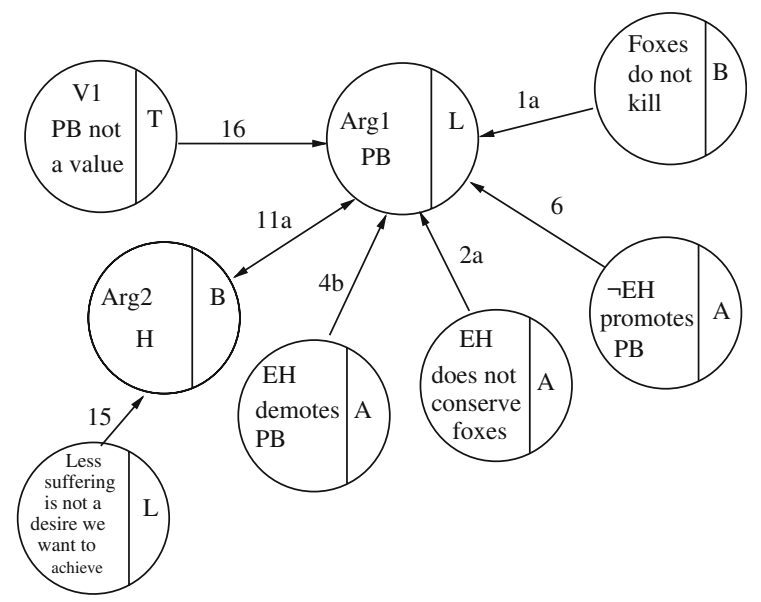

Figure 1. Level 1: Arguments about the world.

described in Greenwood et al. (2003). In expressing the arguments in this paper we have, for readability reasons, avoided repetition of facts by using only the relevant subset of $\mathrm{R}$. This means that we can omit $\mathrm{S}$ altogether as $\mathrm{G}$ comprises this relevant subset, together with the decision taken.

$\operatorname{Arg} 1$

R1: Where foxes kill livestock, encouraging hunting leads to fewer foxes and fewer foxes means farmers are protected

A1: encourage fox hunting

G1: as fewer foxes and farmers protected

V1: promotes public benefit.

Agent L puts forward Arg1 and this is attacked by Arg2 using attack 11a which is put forward by agent $\mathrm{B}$ :

$\operatorname{Arg} 2$

R2: Where fox hunting is cruel

A2: discourage fox hunting

G2: as reduced animal suffering

V1: promotes humaneness.

This argument is mutually attacked by agent L's original statement made in Arg1 but agent $\mathrm{L}$ can also attack it using attack 15 which states that $\mathrm{L}$ does not believe that ,reduced animal suffering' is a desire that we want to achieve. Agent B can also make a second attack by disputing the fact, foxes kill' using attack 1a. Agent A can also attack agent L's Arg1 by using 3 different attacks; attack 4b, $2 \mathrm{a}$ or 6 . Using attack 4b, agent A states his belief that encouraging hunting will demote public benefit, advanced by Livingston, as hunters preserve foxes and destroy crops, both of which are not of benefit to the public. Using attack $2 \mathrm{a}$ he further states that contrary to 
Livingston's belief that there will be fewer foxes if hunting is encouraged, there will in fact be more, as hunters preserve foxes for their sport. Using attack 6 agent $\mathrm{A}$ then states that there is an alternative action of not encouraging hunting, as then foxes will be wiped out by other means of pest control, and fewer foxes promotes public benefit. Finally, agent $\mathrm{T}$ can make attack 16 on Argl by stating that ,public benefit' is not a value we should be trying to promote.

From the argumentation framework in Figure 1 agent $\mathrm{L}$ can, by choosing to rank the value ,public benefit' over ,humaneness' and ,clear law', deduce that hunting should be encouraged and agents B and A can deduce that hunting should be discouraged, using their own preferences. T, by accepting L's argument against Arg2, need subscribe to neither argument, and so derives no additional desires from this level of the debate.

We can now move on to the next level, giving the argumentation framework shown in Figure 2.

This argumentation framework is constructed from the following instantiations of AS1:

Arg3

R3: Where there is pursuit and fox hunting is to be encouraged

A3: find ownership established

G3: as hunting encouraged

V3: promotes public benefit.

Arg4

R4: Where there is pursuit and fox hunting is to be discouraged

A4: find no ownership

G4: as hunting discouraged

V4: promotes humaneness.

$\operatorname{Arg} 5$

R5: Where there is no possession

A5: find no ownership

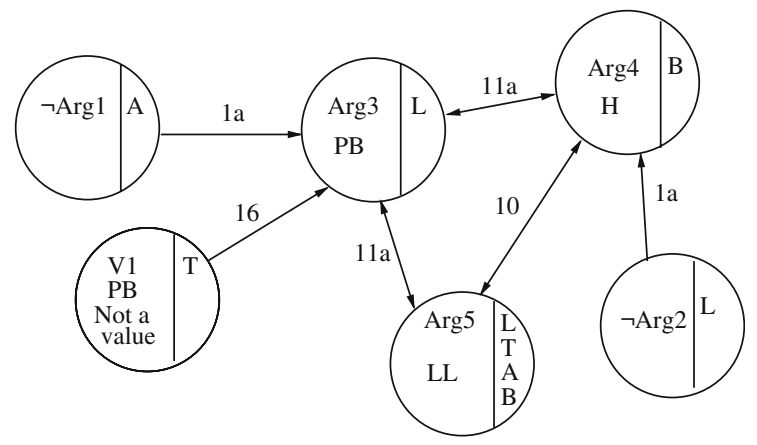

Figure 2. Level 2: Linking to legal concepts. 
G5: as finding no ownership where no possession

V5: promotes less litigation.

Agent L puts forward Arg3. Firstly, this is attacked by agent A using attack 1a, stating that he does not believe Arg1 from the previous framework to be true. Agent $\mathrm{T}$ also attacks Arg3 by using attack 16 which states that ,public benefit' is not a value. There is then a 3-cycle of attacks: all agents using attack 11a to attack Arg3 with Arg5. This is itself attacked by Arg3. The next attack in the cycle is also a mutual one put forward by agent B using attack 10 to state Arg4. Arg4 also mutually attacks Arg3 using attack 11a, which completes the 3 -cycle. However, Arg4 is attacked by agent L using attack 1a stating that he does not believe that Arg2 from the previous framework holds.

Figure 2 debates whether or not ownership is to be attributed on these facts. L uses Arg3 to say that ownership should be attributed, relying on his view of what the facts about foxes are from Level 1 . L uses a preference for public benefit over less litigation to avoid defeat by Arg5. He attacks Arg4, the favoured argument of B, because he does not accept Arg2 from Level 1, since humaneness is not among his values. The attack of $\mathrm{A}$, using attack 1a, can be ignored by $\mathrm{L}$ as it turned on a factual disagreement in the previous level. All except L agree that Arg3 is defeated, although for different reasons, and so accept Arg5. L accepts Arg5, but believes that its force is insufficient to defeat Arg3. We can now move on to the top level arguments, giving the argumentation framework shown in Figure 3.

This argumentation framework is constructed from the following instantiations of argument scheme AS1:

Arg6

R6: Where there is ownership

A6: find for plaintiff

G6: as finding for plaintiff with ownership

V6: promotes less litigation.

Arg7

R7: Where there is no ownership

A7: find for defendant

G7: as finding for defendant where there is no ownership

V7: promotes less litigation.

$\operatorname{Arg} 8$

R8: Where there is malicious interference by defendant

A8: find for plaintiff

G8: as finding for plaintiff where there is malicious interference condemns immoral behaviour

V8: which promotes public benefit. 


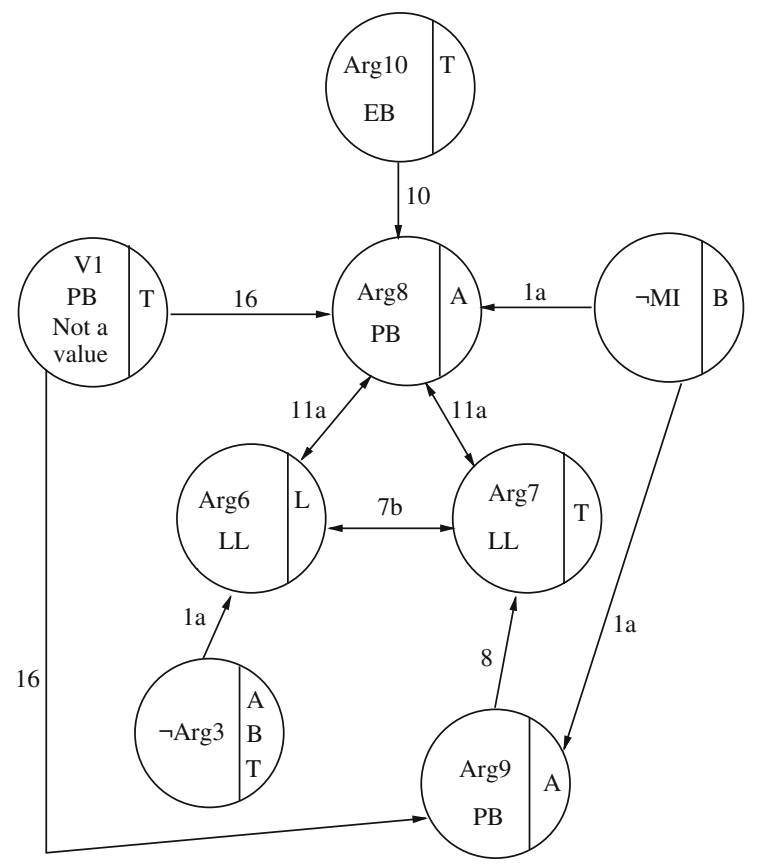

Figure 3. Level 3: Arguments in terms of legal concepts.

Arg9

R9: Where there is malicious interference by defendant

A9: do not find for defendant

G9: as finding for defendant where there is malicious interference condones immoral behaviour

V9: which demotes public benefit.

$\operatorname{Arg} 10$

R10: Given the facts of Keeble

A10: do not find for defendant

G10: as finding for defendant where there is malicious interference and productive activity

V10: demotes economic benefit.

Agent L puts forward Arg6. This is immediately attacked by all of T, B and $\mathrm{A}$ who, for their different reasons, did not accept Arg3 from the previous framework and therefore deny its premise. Next, agent A, who wishes to find for Post not on grounds of the protection of farmers but to condemn Pierson's interference in Post's sport, uses attack 11a to state Arg8 (which is mutually attacked by Arg6), but this is in turn attacked by agent T's attack 16 and also by agent B's attack 1a stating that he does not believe that the 
interference was malicious. Agent $\mathrm{T}$ can make attacks $11 \mathrm{a}$ and $7 \mathrm{~b}$ on $\mathrm{Arg} 8$ and Arg6 respectively by stating Arg7, which is his main argument, based on his acceptance of Arg5 at the previous level. This creates a 3-cycle of attacks between schemes Arg6, Arg7 and Arg8. However, Arg7 is then attacked by agent A using attack 8 which states Arg9. Like Arg8 this can be attacked by the two existing nodes in which agent $\mathrm{T}$ uses attack 16 to say ,public benefit' is not a value and agent B uses attack 1a to state that he does not believe that there was malicious interference.

The one precedent explicitly cited in the decision is Keeble. The role of Keeble is to provide support for Arg8, in the manner described in Greenwood et al. (2003). This, however, can be attacked using attack 10 as described in that paper, as the finding for the plaintiff can be motivated either by desire 3 from Table I, as Keeble was engaged in a profitable enterprise, or by a desire expressing protection of property rights. These alternative interpretations of Keeble, could be added to the framework: in Figure 3 we have added the first of them as Arg10, making attack 10. We do not represent the second challenge here as we have not represented any beliefs or desires relating to property.

This now completes the final framework and so we can deduce, with respect to each of our various agents, whether the plaintiff has remedy or not. L, who accepts Arg3, and gives prime importance to public benefit will use Arg6 to determine his decision. A, who also gives primacy to public benefit, but rejects the facts on which Arg6 is ultimately based will use Arg8. B rejects the premises of both Arg6 and Arg8, and so he finds Arg7 acceptable. Finally, T accepts Arg7 as it is the only argument grounded on a value of which (in his opinion) the law should take note.

\section{Relating our arguments and the opinions}

In this section we will return to the opinions summarised in Section 3, and relate them to the various components of the argumentation frameworks produced in the previous section. We begin by relating the arguments and attacks put forward by $\mathrm{T}$ and $\mathrm{L}$ in these frameworks to the opinions of Tompkins and Livingston. We will also need to consider the arguments of A at Level 3, since these are referred to by Tompkins in order to be rejected. At Level 3, A can be seen as the representative of the hunting aficionado, and his arguments reflect those that we might expect Post, or his counsel, to advance. We do not expect to be able to reflect the structure of the opinions, nor, of course, the extraordinary language used to deliver them, but we do hope to identify the reasoning elements corresponding to T1-8 and L1-5.

We will begin by considering the opinion of Tompkins. We will proceed top down, as this corresponds most closely to the structure of that opinion. 
Therefore, consider first Figure 3. Tompkins must primarily dispose of alleged precedent cases, represented in Figure 3 by Arg8. He first dismisses a number of cases as irrelevant (T3) and distinguishes Keeble (T5). Since we do not know the cases referred to in T3 or which argument they were supposed to support we have not represented them here. The attacks on the interpretation of Keeble in T5 are represented by Arg10. Once the alleged precedent has been dismissed, Arg8 can be eliminated by denying that its value is a proper concern (V1 in Figure 3). This corresponds to T7, "no injury or damage for which a legal remedy can be applied". With Arg8 eliminated, the question turns on whether the premises of Arg6 or Arg7 are accepted. This is the question expressed in T1, and which is answered in the framework of Figure 2.

In the framework at Level 2, T adopts only Arg5, that the law is clear that where there is no possession there should be no ownership. That the law is clear on this point and that there are neither cases nor authorities to suggest that pursuit of a wild animal may constitute ownership, is the point of T2 in Tompkins' opinion. The conclusion that mere pursuit cannot count as ownership is explicitly expressed at the end of T4. The purpose motivating Arg5 is expressed in T6, "for the sake of certainty".

This relates all seven components of Tompkins' opinion to our agentbased account. T1 states the choice to be made at Level 3, T2 and T4 provide the factual basis of $\operatorname{Arg} 5$, which is then motivated by the value supplied in T6, and which leads to a denial of a premise in Arg6. T3, T5 and T7 remove unfavoured arguments from Level 3. Tompkins, like $\mathrm{T}$, has no need to descend to the issues raised at Level 1.

Turning now to Livingston, he first agrees with Tompkins' view of Level 3 (L1). L2 seems to endorse the opinion that the case should never have come before a court, and suggests that in a tribunal of sportsmen, Arg8 would be followed. In a court, however, clarity of law is important, and we take this an acceptance of the force of Arg5, which is motivated by a desire to reduce the potential for these matters to be litigated. Livingston's main argument is Arg1, stated and motivated in L3, to kill foxes "is allowed to be meritorious, and of public benefit", the value being expressed again at L5. L4 is concerned to argue that the court may make the law (because only if this is so, are Level 1 concerns able to be introduced). It is this which expresses the preference of public benefit over less litigation, which is necessary if Arg3 is to succeed over Arg5. He suggests that the public benefit was not recognised by Justinian only because fox hunting was not then in fashion. Had it been, "the lawyers who composed his institutes would have taken care not to pass it by, without suitable encouragement".

Tables IV and V summarise this discussion by listing the components of the argumentation framework, together with the agent that introduced them, and the section of the opinion which they represent. These tables show that 
Table IV. Arguments introduced (or mentioned if starred) in opinions

\begin{tabular}{lll}
\hline Argument & Agent & Opinion section \\
\hline Arg10 & T & T5 \\
Arg9 & A & T7* \\
Arg8 & A & T5* \\
Arg7 & T & T1 \\
Arg6 & L & L1 \\
Arg5 & T, L, A, B & T2, T6 \\
Arg3 & L & L4 \\
$\neg$ Arg3 & T, A, B & T4 \\
Arg1 & L & L3, L5 \\
V1 (value 1) & T & T7 \\
\hline
\end{tabular}

Table $V$. Attacks made (or mentioned if starred) in opinions

\begin{tabular}{lllll}
\hline Attack & Attacker & Attacked & Agent & Opinion section \\
\hline 10 & Arg8 & Arg7 & A & T7* \\
$7 \mathrm{~b}$ & $\operatorname{Arg} 7$ & $\operatorname{Arg} 6$ & $\mathrm{~T}$ & $\mathrm{~T} 1$ \\
$1 \mathrm{a}$ & $\neg \operatorname{Arg} 3$ & $\operatorname{Arg} 6$ & $\mathrm{~T}, \mathrm{~A}, \mathrm{~B}$ & $\mathrm{~T} 4$ \\
16 & $\mathrm{~V} 1$ & $\operatorname{Arg} 8$ & $\mathrm{~T}$ & $\mathrm{~T} 7$ \\
10 & $\operatorname{Arg} 10$ & $\operatorname{Arg} 8$ & $\mathrm{~T}$ & $\mathrm{~T} 5$ \\
$11 \mathrm{a}$ & $\operatorname{Arg} 3$ & $\operatorname{Arg} 5$ & $\mathrm{~L}, \mathrm{~T}, \mathrm{~A}, \mathrm{~B}$ & $\mathrm{~L} 4$ \\
\hline
\end{tabular}

each of the sections of the opinion can be linked to a component in the framework, with the exception of T3 and L2. T3 is similar to T5, but is omitted because, unlike Keeble, we do not have sufficient information about the cases dismissed as irrelevant to represent them. L2 is something of an aside, expressing sympathy with Arg8, whilst recognising that it cannot prevail over Arg7 in a court of law since for $\mathrm{L}$, consideration of public benefit is proper to Level 2.

Of the arguments in the frameworks, $\neg \mathrm{MI}$ (,no malicious interference') from Level 3 is omitted, as are Arg4 and $\neg$ Arg2 from Level 2 and all except Arg1 from Level 1. $\neg \mathrm{MI}$ and Arg4 are proposed only by B and so represent a point of view which emerged after the decision. Similarly $\neg$ Arg2, although attributed to L, appears only in order to attack Arg4. At Level 1, in the actual case no challenge was made to Livingston: again the arguments reflect later discussions. Thus all the reasoning moves in the framework that address concerns that arose at the time of the case are reflected in the opinions.

Note that Tompkins confines his considerations to Levels 2 and 3, whereas Livingston, who needs to argue instrumentally, must start at Level 1 
with a discussion of the way of the world. Our other two agents operate mainly at Levels 1 and 3, reflecting the fact that they are not producing essentially legal arguments. A disagrees with $\mathrm{L}$ about the facts of the world (not the facts of the case), suggesting that fox hunting does nothing to reduce the fox population. At Level 1 he argues for a sense of what is fair over the legal question which Tompkins addresses. B argues from a moral rather than a legal perspective, using a general moral value at Level 1 and a coloured interpretation of the facts of the case at Level 3.

Since (Berman and Hafner 1993), in AI and Law discussion of Pierson and Keeble has also mentioned Young v. Hitchens, 1 Dav and Mer. 592Q.B. 6060 (1844), a case where a commercial fisherman was interfered with by a competitor who managed to intercept the fish he was on the point of landing. We should perhaps also say something about this case. Here the fact that Young was engaged in commercial fishing rather than sport brings desire 3 from Table I into the question and so allows this to motivate an argument equivalent to our Arg8 in terms of economic benefit, and makes Keeble much more plausible as a precedent. It appears that Tompkins may not have dismissed the interference in the terms he did were there a question of financial damage. On the other hand, Level 1 will be entirely different in Young. In particular, although Young does suffer financial damage, the public do not suffer, since they can purchase the fish from Hitchens as well as Young. Thus there is no argument to ground Arg3 at Level 2: commercial fishing is neither encouraged nor discouraged by finding for the plaintiff, since both plaintiff and defendant are engaged in the activity. Thus although the question of economic benefit can be raised, it cannot motivate an argument at this level. Keeble is structurally rather closer to Pierson at Level 1: there the actions of the defendant do serve to reduce the supply of ducks to the public, but the activity of Keeble had a direct economic benefit which provided a stronger reason to accept the argument than was available to Post. The question in Young therefore turns on whether the strengthened Arg8 defeats Arg7. Arg6 does not appear since Arg3 is not available as its premise. It seems from the account of Patteson's opinion given in Berman and Hafner (1993) the court was reluctant to pronounce on what constituted unfair competition. Accepting Arg8 over Arg7 in Young would effectively denounce Hitchen's actions as unfair.

\section{Levels of reasoning}

One of the main features to emerge from the above reconstruction of these two opinions was that the reasoning naturally formed three connected layers. The uppermost layer (Level 3) was concerned with legal concepts and the rights they conferred. In the particular opinions, disagreement at this level 
was based solely on whether or not ownership was ascribed: once this point was decided the consequences were clear and there were no conflicting considerations. The second layer (Level 2) concerned the ascription of these legal concepts, given the particular facts of the case under consideration. Here arguments for and against ascription of the legal concepts can come either from precedents (although there were no applicable precedents in the particular case), or from purposes derived from reasoning in the bottom layer (Level 1).

At Level 1 people reason about the world in order to determine what the law should be, and conclusions from this level are used at Level 2. Note that Tompkins, who is content with the status quo, has no need to descend to Level 1, while Livingston, who wishes to extend the concept of ownership beyond what is covered by the current precedents, needs to motivate his arguments at this level. These three levels of reasoning are shown diagrammatically in Figure 4 and we will go on to discuss the features of these levels of reasoning in more detail.

Legal reasoning begins with facts and ends with legal conclusions. The law is typically stated in terms which cannot be directly equated with facts. Thus under the 1975 Social Security Act, a person is entitled to Sickness Benefit:

"in respect of any day of incapacity for work which forms part of a period of interruption of employment".

In the Restatement on Torts: "One who discloses or uses another's trade secret, without a privilege to do so, is liable to the other if:

(a) he discovered the secret by improper means, or

(b) his disclosure or use constitutes a breach of confidence reposed in him by the other in disclosing the secret to him, or

(c) he learned the secret from a third person with notice of the facts that it was a secret and that the third person discovered it by improper means or that the third person's disclosure of it was otherwise a

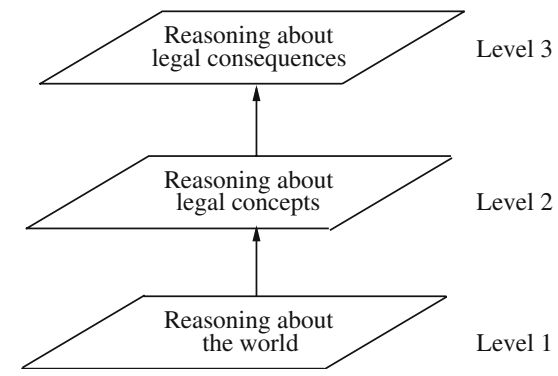

Figure 4. The three levels of legal reasoning emerging from the reconstruction of Pierson v. Post. 
breach of his duty to the other, or

(d) he learned the secret with notice of the facts that it was a secret and that its disclosure was made to him by mistake".

Terms such as "incapacity for work", "period of interruption of employment" and "trade secret" are all terms of art, the application of which must be determined in the light of facts.

The need to make the transition from facts about the world to legal concepts was a major concern of expert systems designers in the 1990s. For example the work of Breuker and his group (e.g. Breuker and den Haan 1991), explored the need to represent knowledge of the world, knowledge of legal concepts and the connections between them. Work on legal expert systems in the logic programming tradition (e.g. Bench-Capon 1991b), tended to begin with a definition of the terms of the legislation, and then unpack the definitions of these terms using sufficient conditions expressed in factual terms taken from case law and expert guidance. These strands of work arose from a response to practical problems of designing and building legal expert systems. A recent paper by Lindahl (2004), gives a nice formal expression to these notions. Lindahl describes a legal inference as having the form:

$$
\begin{aligned}
& a \rightarrow b \\
& b \rightarrow c
\end{aligned}
$$

Therefore $a \rightarrow c$.

and calls $b$ the middle term, linking $a$ to $c$.We shall use the "intermediate concept" to describe the middle terms. Lindahl argues that many legal inferences are of this form. Intermediate concepts such as "ownership" (or "trade secret" or "period of interruption of employment") play the role of these middle terms. Then, following Ross (1951), he says that several fact situations can typically fill the role of $a$ for a given $b$, and that typically any given $b$ will allow the deduction of several $c$ s. The importance of intermediate concepts and their treatment in Ross was discussed by Ashley and Brüninghaus (2003). They stressed the vital role played by intermediate concepts in predicting the outcome of cases. Their idea there is that the decision is predicted on the basis of the intermediate concepts which apply, and the factor-based reasoning taken from CATO is mainly used to establish which intermediate concepts apply. This has clear correspondences with our Level 3 , where the intermediate concepts are applied, and our Level 2 where the presence of intermediate concepts is established. However, their approach uses case-based reasoning whereas we rely on a model of practical argumentation, and they also make no appeal to purpose.

Lindahl then discusses how such intermediate concepts can be defined and mentions first direct enumeration, whereby a set of concrete examples of "being a $b$ " are listed, and definition by regulation, whereby the terms are 
defined in greater detail by secondary legal sources. We might also see case law (at least as used in the Sickness Benefits case) as offering this kind of definition of these sorts, where a particular case provides a particular example which can be seen as part of an enumeration, and the ratio decendi of a case is akin to definition by regulation. ${ }^{5}$ If such decisions are to act as precedents, this is a good way to see them.

Examples of definition by regulation through secondary legislation and through case law are abundant in Sickness Benefit. For an example of secondary legislation, Regulation 3(1) of the Social Security (Unemployment, Sickness and Incapacity Benefit) Regulations 1983 provided that a person undertaking therapeutic work as part of supervised programme of treatment while a patient in or of a hospital should be considered incapable of work. As an example of case law it was held in $\mathrm{R}(\mathrm{S}) 3 / 52^{6}$ that a patient attending hospital as an outpatient every two months should be considered a patient of a hospital in the intervening period.

It was this style of definition that underlay the thinking of expert systems constructed in the manner of Bench-Capon (1991b). As Lindahl has subsequently pointed out (Lindahl and Odelstad 2004), there is another important type of "definition" whereby a set of factors to be considered, explicitly stated to be individually neither necessary nor sufficient, is given. The Restatement of Torts comment (b) provides an excellent example of this:

"Some factors to be considered in determining whether given information is one's trade secret are:

1. the extent to which the information is known outside of his business;

2. the extent to which it is known by employees and others involved in his business;

3. the extent of measures taken by him to guard the secrecy of the information;

4. the value of the information to him and to his competitors;

5. the amount of effort or money expended by him in developing the information;

6. the ease or difficulty with which the information could be properly acquired or duplicated by others". (italics ours)

Factors of this kind and their combination are not straightforwardly represented in the rule-based approach, and it is intermediate concepts of this type that have featured prominently in case-based approaches, such as Aleven (1997) and Ashley (1990).

Relating this work to the levels of the reconstruction of Pierson v. Post as described above, we can see that Level 3 is concerned with Lindahl's $b \rightarrow c$, the calculation of consequences from legal terms, and Level 2 is concerned with Lindahl's $a \rightarrow b$, the determination of which intermediate legal concepts apply given the case facts. So where does Level 1 fit in? This kind of 
reasoning does not occur in legal expert systems, because they work with a body of existing law (or an interpretation of it) and are not at all concerned with what the law should be or whether the conclusions are desirable. Such systems take the law as given and allow no deviation from it (Bench-Capon 1989). In Bench-Capon (1991a), these two levels were encased in two others: the level of political debate which determines that a law should be made (e.g. it is desirable to maintain the income of the sick), or at which law is criticised (e.g. $\mathrm{R}(\mathrm{S}) 4 / 56$ in which a young woman who had been in receipt of sickness benefit for two years in respect of agoraphobia was held not to be incapable of work on the ground that she could work as an outworker in her own home, would seem rather harsh today). These are important debates, but are often held to fall outside the scope of legal knowledge-based systems. They are, however, examples of Level 1 reasoning. Level 1 reasoning arises therefore when a change in the law is being proposed or considered.

This can arise during the consideration of a case since it is a fact that judges can, and often do, use discretion, and there is the phenomenon of "judge made law". The extent to which judges are permitted, or even encouraged, to exercise such discretion varies from jurisdiction to jurisdiction, according to legal culture, and will also vary within a jurisdiction from time to time. Moreover, different judges will be more or less reluctant to exercise such discretion. None the less, it is clearly this notion of changing the law to meet some notion of what is right that underlies Livingston's argument in Pierson: he explicitly says "if men themselves change with the times, why should not laws also undergo an alteration?" and is in no doubt of the power of the court to effect this alteration.

This means that Level 1 will not come into play in all cases, but only where one of the judges wishes to challenge the apparent status quo. Since it is at this level that social values, as opposed to legal principles, are at their most important this may help to explain the observation made in Branting (2003) that values are little spoken of in the majority of judicial decisions. Nonetheless, such explicit appeal to values, which we have identified as Level 1 reasoning, does occur. An excellent example is provided by the decisions in the US Supreme Court case of Furman v. Georgia 408 U.S. 238 (1972). The case was considering the question of whether the death penalty is a cruel and unusual punishment prohibited by the Eighth Amendment to the United States Constitution. Mr Justice Marshall's concurring decision is very long and takes one on a historical tour of many aspects pertinent to the case including capital punishment and the use of the word "cruel", but his key question is "whether capital punishment is "a punishment no longer consistent with our own self-respect"" (italics ours). He concludes one section of his discussion with "It is immediately obvious, then, that since capital punishment is not a recent phenomenon, if it violates the Constitution, it does so because it is excessive or unnecessary, or because it is abhorrent to currently 
existing moral values" (italics ours). Another section concludes "To answer this question, we must first examine whether or not the death penalty is today tantamount to excessive punishment" (italics ours). Again he says "it nonetheless violates the Eighth Amendment because it is morally unacceptable to the people of the United States at this time in their history" (italics ours). He concludes that by striking down capital punishment "We achieve ,a major milestone in the long road up from barbarism". The whole thrust of his decision, which he himself describes as "a long and tedious journey", is to show that the law develops and progresses as times change, and it is the role of judges such as himself to mark those changes.

The concurring judgement of Mr Justice Brennan, similarly emphasises the need to look at the matter with contemporary eyes:

"When this country was founded, memories of the Stuart horrors were fresh and severe corporal punishments were common. Death was not then a unique punishment. The practice of punishing criminals by death, moreover, was widespread and by and large acceptable to society. Indeed, without developed prison systems, there was frequently no workable alternative. Since that time, successive restrictions, imposed against the background of a continuing moral controversy, have drastically curtailed the use of this punishment. Today death is a uniquely and unusually severe punishment. When examined by the principles applicable under the Cruel and Unusual Punishments Clause, death stands condemned as fatally offensive to human dignity". (italics ours)

In contrast, the dissent from Mr Justice Burger begins:

"If we were possessed of legislative power, I would either join with MR. JUSTICE BRENNAN and MR. JUSTICE MARSHALL or, at the very least, restrict the use of capital punishment to a small category of the most heinous crimes. Our constitutional inquiry, however, must be divorced from personal feelings as to the morality and efficacy of the death penalty, and be confined to the meaning and applicability of the uncertain language of the Eighth Amendment". (italics ours)

For Burger the judges do not have the scope of discretion that Brennan and Marshall take upon themselves, and "the highest judicial duty is to recognize the limits on judicial power and to permit the democratic processes to deal with matters falling outside of those limits".

This pattern, whereby disagreement resides in whether or not Level 1 reasoning is appropriate, leads to the narrowly legalistic approach, exemplified by Tompkins in Pierson, being set against an appeal to social values as 
a motive to make or change the law, exemplified by Livingston in Pierson, and is not uncommon.

\section{Modes of disagreement}

At Level 3 there is often little scope for disagreement: typically once the applicability of the intermediate terms has been discovered, the consequences follow in an agreed manner. Any disagreement that does occur will turn on a conflict of norms: two legal concepts are considered to be applicable and they have conflicting consequences. Such conflicts may be resolved through the use of precedent, or legal principles such as lex superiori. This is shown diagrammatically in Figure 5.

At Level 2 there is again scope for conflict, if definition by regulation has provided sufficient conditions for ascribing the concept and sufficient conditions for withholding it, both of which are satisfied in a particular case. Here the conflict is typically resolved either through the use of legal principles, or by choosing between the precedents. At this level there is also the possibility of a gap, where no definition covers the case at hand, as shown in Figure 6. Here one either takes a default, withholding the concept if no conditions for its attribution are satisfied, or one can extend the scope of the concept: it is when this second option is taken that descent to Level 1 is required, to motivate the extension. Conflicts and gaps form the "hard cases" of Gardner's pioneering work (Gardner 1987).

Where the definition is not in terms of sufficient conditions, but in terms of a set of factors to consider, as in the case of "trade secret", analogous situations arise. One way to see such cases is a kind of scatter plot where precedents are positioned according to the extent to which the various factors apply. Figure 7 shows such a plot for two factors, with "Y" representing cases where the concept was applied and "N" cases where it was withheld. We would expect there to be a region occupied only by " $Y$ " and a region occupied only by "N", but between them "Y"s and "N"s would be entangled. This is the region where hard cases are found. In the case of intermediate concepts of this kind, however, we can have no expectation of drawing

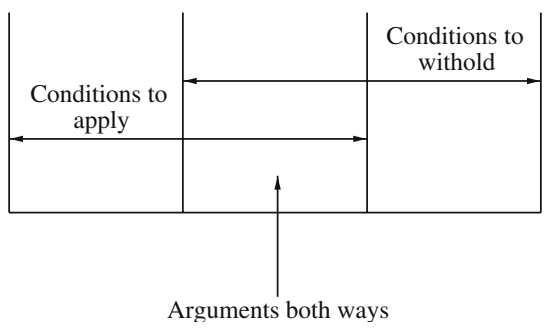

Figure 5. A conflict in arguments. 


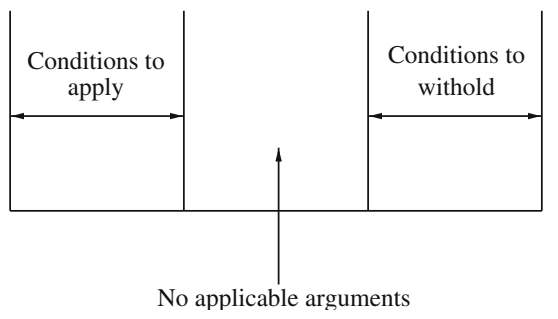

Figure 6. A normative gap.

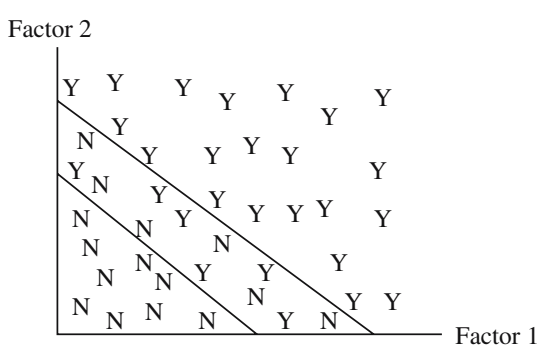

Figure 7. Hard cases in factor-based domains.

a sharp line to separate the two regions, rather we have, to use Hart's famous analogy (Hart 1961), two cores of certainty and a penumbra of doubt between them. This is the situation - particularly as we move into higher dimensional spaces with the need to consider more factors - which makes the notion of matching to closest precedents particularly attractive.

Finally there may be disagreement at Level 1, but here the debate will concern what should be encouraged, and has the character of a political argument, turning on values, rather than a purely legal argument.

\section{The role of precedents}

In this section we turn to the question of how precedents fit in with our account, and how they relate to the levels of reasoning discussed above. Since we proceed by generating instantiations of argument schemes from the beliefs and current facts of the agents, it is at first sight hard to see how precedents can play a role. This is, however, to overlook the fact that part of the knowledge of the agents has to derive from previous cases.

\subsection{INTERMEDIATE CONCEPTS DEFINED BY REGULATION}

Consider first Sickness Benefit, and decision R(S) 13/54:

"A disabled man with an a artificial leg was unable to get to his place of work for some days because of a heavy fall of snow. It was held that he 
was not incapable of work by reason of his bodily disablement and that sickness benefit was not payable to him". (Neligan 1979, 2.2.7)

This decision can be converted into a rule recognising the existence of the precedent, whereby we can say that the fact that the illness renders the claimant incapable of travel to work rather than the work itself is a sufficient condition to state that the claimant is not incapable of work, so as to promote consistency.

In terms of our argument scheme :

A1:

where capable of work and incapable of travel and $\mathrm{R}(\mathrm{S}) 13 / 54$

find no incapacity for work

as capable of work and incapable of travel and no incapacity for work

promotes consistency.

We will therefore represent our agents as having a desire to follow precedents, so as to promote consistency, and the conditions for the desire to be satisfied will be the fact situation of the precedent, the precedent and the legal qualification made by the precedent. Representing precedents in this way is rather similar to the way in which case law is represented in traditional expert systems such as Bench-Capon (1991b).

An argument such as A1 can of course be attacked using critical questions, as described above in the reconstruction of Pierson v. Post. Such critical questions can be used to attack precedents in ways corresponding to the standard argument moves in case-based systems such as HYPO. Chief among these are distinguishing and providing a counter example. We begin with distinguishing. In Greenwood et al. (2003) we identified four of the critical questions as making distinguishing moves of various sorts (differentiated as to whether the distinction resulted from a strength in the precedent absent from the current case or a weakness in the current case, and as to whether the distinction could be emphasised or downplayed).

Suppose the man concerned in R(S) 13/54 was unable to travel because of a defect in the artificial leg rather than the weather conditions, although he could do his work once at the office. This might be held to be good enough (defects in prosthesis can be treated as bodily disablement in certain cases).

Now we can attack A1 with the argument:

\section{A2:}

where incapable of travel and ineffective prosthesis

find incapacity for work

as ineffective prosthesis and incapacity for work

promotes income maintenance.

Note that this argument proposes a value promoted by satisfying the goal. This reflects the fact that, as discussed at length in Aleven (1997), not any difference between two cases will serve to distinguish a precedent. If the value 
is acceptable, then A2 will defeat A1: when evaluating arguments we give consistency a weak ranking to reflect that precedents need not be followed if they can be distinguished. But the debate is not yet finished. In the original decision $\mathrm{R}(\mathrm{S})$ 13/54 there will have been a motive for deciding the case in the manner chosen. Therefore, in the previous decision there must have been a Level 1 argument for finding that no incapacity should be attributed in the circumstances of that case, and so that decision will have been based on a value, perhaps the need to safeguard the contributors to the National Insurance Fund. This argument will still apply in the new case, and so we will have a conflict at Level 1, and we will need to choose between the values of $A 2$, and of the original argument underlying $R(S)$ 13/54. If we choose to prefer the value of that argument over the value of $\mathrm{A} 2$, we will reject the distinction. If the distinction is accepted, it has the effect of moving the case into the gap not already covered by previous decisions, and so Level 1 reasoning is needed to motivate how the gap should be narrowed, if indeed it should be narrowed at all. If the distinction is rejected, we effectively say that the case does not fall in the gap, is already covered by past decisions, and hence the reasoning can remain at Level 2.

Suppose we choose in favour of the argument based on the distinction and decide for the claimant on the basis of $\mathrm{A} 2$, and report the decision as, say $\mathrm{R}(\mathrm{H}) 1 / 05$. Now that decision will become a precedent itself. In any subsequent case in which the facts of $\mathrm{R}(\mathrm{H}) 1 / 05$ are satisfied, there will be two conflicting and applicable precedents, $\mathrm{R}(\mathrm{H}) 1 / 05$ and $\mathrm{R}(\mathrm{S}) 13 / 54$. Here we will probably not wish to revisit the Level 1 reasoning: we are likely to follow $\mathrm{R}(\mathrm{H}) 1 / 05$ on the grounds that it is favoured both as the more specific law and as the more recent law. Normally, therefore, conflicting precedents will be decided at Level 2 using such principles, although the opportunity to descend to Level 1 remains. Where we have two conflicting precedents, we are making a counter example move. In the example, citing $\mathrm{R}(\mathrm{S}) 13 / 54$ is likely to be ineffective, because $\mathrm{R}(\mathrm{H}) 1 / 05$ trumps $\mathrm{R}(\mathrm{S}) 13 / 54$, but if the conflict could show features present in the counter example that are not present in the original precedent, there would be a need to resolve the matter using the value preferences shown in the Level 1 reasoning.

The need to descend to Level 1 is required not only to address nontrumping counter examples, but also for the law to be able to change to meet changing social circumstances, as advocated by the majority decisions in Furman cited above. In fact, however, the freedom to revisit the Level 1 reasoning depends on the Court and the rules under which it operates. In the UK, the House of Lords (since its Practice Statement 1. W.L.R. 1234 of 1966 ) is not bound by its previous decisions, and may depart from precedents if it is believed that there is good reason so to do. In other words, the House of Lords is always free to descend to Level 1 if it chooses to do so, although this freedom is exercised sparingly in practice. In contrast the Court of 
Appeal is usually, following the opinion of Greene M.R. in Young v. Bristol Aeroplane Co Ltd (2 All E.R. 293) in 1944, considered bound by previous decisions of the Court, except where certain exceptions apply. In the case of Social Security, all lower courts are bound by decisions of superior courts, but decisions at a given level are not binding. Thus there is a possibility of different Commissioners giving conflicting decisions, based on different choices of Level 1 values. When such conflicts arise it is normal to convene a Tribunal of three Commissioners, the decision of that Tribunal then binding the Commissioners, or the legislation may need to be changed to clarify the situation.

So far we have we have considered moves concerning the application of intermediate legal concepts. Here a conflict is introduced at Level 2 and resolved potentially by considering purposes at Level 1 . There is also the possibility of conflict at Level 3, when two intermediate terms conferring conflicting rights are both applicable at Level 2. For example a person may satisfy the conditions to receive Sickness Benefit, while also being in a situation where the Fund is entitled to withhold it, for example if the illness arises from what is judged to be "misconduct". Here the resolution is typically controlled by some statutory provision. Where this is not so, resolution can either be through applying legal principles, or through consideration of the competing precedents at Level 2 . There we can apply principles such as the more specific or more recent law, or trace the values underlying these precedents back to Level 1 , so that a choice can be made between them on the basis of these values.

The above discussion of Sickness Benefit concerns an area of law which is intended to be governed by rules, and the decisions act as clarifications of the rules. The style of definition of these concepts shows that it is intended that the intermediate concepts found at Level 2 be capable, in principle, of being given necessary and sufficient conditions. Case law in this domain can be seen as elaborating those conditions to meet circumstances not foreseen in the original drafting, or to decide them in ways concomitant with the prevailing social mood.

\subsection{INTERMEDIATE CONCEPTS DEFINED BY SETS OF FACTORS}

The use of precedents in an area with no sufficient and necessary conditions, such as the notion of trade secret is somewhat different. Here we are supposed to consider a set of aspects, none of which can be considered decisive. None of the six factors which need to be considered according to comment (b) from the Restatement of Torts, is capable of being given a yes/no answer. They relate to "the extent to which" or the "ease with which". It is thus 
apparent that we are not dealing with sharp concepts, but concepts which are satisfied to greater or lesser degrees.

This notion was at the heart of the HYPO system (Ashley 1990), which introduced the notion of dimensions to represent differing degrees of satisfaction. Each of the six factors could have formed a dimension in HYPO, although in practice while factors 1,3 and 6 correspond closely to dimensions, and 4 and 5 represent two aspects of another, the second factor does not form an explicit dimension. (The other nine dimensions in HYPO correspond to considerations that make a person liable for disclosure if the information is considered a trade secret.) This notion of degree of satisfaction was not explicitly represented in CATO (although several of the "factors" used in that program can be seen as points on a HYPO dimension), but it has been revived in more recent work. The system IBP (Brüninghaus and Ashley 2003) distinguishes between three kinds of factor (weak, normal and knockout) which might be seen as representing differing degrees of satisfaction, and the empirical investigations of A. H. Chorley and T. J. M. Bench-Capon (submitted) indicate that assigning weights to factors in a manner corresponding to their location on dimensions improves the quality of explanatory theories in this domain.

Although the approach in Atkinson et al. (2004a) allows for different degrees of belief and promotion of values, we have not as yet performed any experiments on this sort of legal argumentation, and so we will discuss this style of definition no further here.

\section{Separation of issues}

In HYPO no attempt to divide cases into issues was made. In CATO, issues emerged through the structuring of factors into a factor hierarchy, in which abstract factors correspond to elements taken from the Restatement on Torts. In IBP the recognition of the need to consider issues separately is taken a step further and the Restatement of Torts is used to provide an explicit top level model in terms of issues.

Similar structuring is apparent in our approach. The top level, Level 3, resolves issues, on the basis of the attribution of intermediate concepts at Level 2. Although in Pierson there is a single issue (whether or not Post owned the fox), in dealing with Sickness Benefit the issues of incapacity for work and period of interruption of employment could both potentially appear. It is important to separate out issues in this way, since no amount of support for incapacity for work would suffice to give title to Sickness Benefit if the latter condition were unsatisfied. The case is different for determining the application of intermediate concepts defined in the manner of "trade secret": it might, for example, be acceptable to compensate for 
minimal security measures with a clear satisfaction of some of the other factors. This reasoning, however, will take place at Level 2, each cluster of factors separately determining which intermediate concepts can be used at Level 3. Therefore, another advantage of using levels to structure the reasoning it that it allows us to keep considerations which can be used to compensate for one another together, and away from those which they should not affect.

\section{Other related work in $\mathrm{AI}$ and Law}

In addition to the levels of reasoning discussed above, the work in this paper draws on a number of other themes from AI and Law. In this brief section we will make some pointers to this foundational work.

Argument schemes, most notably that of Toulmin (1958), have been used in a number of AI projects, of which the earliest were Marshall (1989) and Lutomski (1989). Toulmin's scheme is quite general, but is concerned with the inference of facts rather than practical reasoning. In its original form, it permits only one kind of attack, based on an argument for the negation of the claim. Extensions, such as used in Bench-Capon and Stainford (1995), allowed for undercutters, by adding elements to the scheme, and for premise defeat, by allowing chaining of the schemes. Critical questions have been used explicitly in connection with other argument schemes, especially the schemes from witness testimony and the scheme from expert opinion, in e.g. Verheij (2003) and Prakken et al. (2003). Again, however, these concern inference of facts: the explicit use of argument schemes to justify actions was used in Greenwood et al. (2003).

The use of values derives from the important paper (Berman and Hafner 1993) which also included Pierson in the cases discussed, and was revived in a group of three papers by Bench-Capon (2002b), Sartor (2002) and Prakken (2002). This strand of work is most fully described in Bench-Capon and Sartor (2003). The contribution of this paper is to use the argument scheme to relate values to arguments in an explicit way, and to construct value-based arguments.

Argumentation frameworks, in the style proposed by Dung (1995) were first used to explore the dialectic status of groups of arguments in Prakken and Sartor (1996). They were used to model a set of cases including Pierson in Bench-Capon (2002a), based on the analysis of Bench-Capon and Rissland (2001). The same cases were also modelled using VAFs in Bench- Capon (2003b). In this work the structure of arguments was left entirely abstract, (Bench-Capon 2002a, 2003b), or seen as a sequence of inferences (Prakken and Sartor 1996), with the standard attacks of rebuttal and undercut. Instantiating the arguments with a scheme designed for practical reasoning 
and generating attacks through the critical questions on this scheme is one of the contributions provided by this paper.

\section{Concluding remarks}

In this paper we have used an approach to modelling practical reasoning and persuasive argument to reconstruct the reasoning in a well-known legal case, and, we have also discussed how the levels of reasoning which emerged from the reconstruction can be used to give insight to reasoning with legal cases more generally.

Our aims of the reconstruction were twofold: to show the feasibility of construing legal argument in terms of our argument scheme for practical reasoning and the critical questions which can be posed against instantiations of it, and to provide a domain to exercise our proposals to realise such debates as a multi-agent system with the different agents representing divergent beliefs, desires and values. We believe we have been successful in these aims.

Looking towards practical realisation, the major difficulty seems to arise from the extensive knowledge representation required to model the instrumental reasoning at Level 1 . It is difficult to imagine this kind of knowledge being available in advance of the case. For a particular case, however, it is less difficult to construct the fragment required to drive the reasoning in a particular circumstance. Thus it would be possible to analyse particular cases in this way, as we have done here. Such an analysis provides a useful way of identifying the possible points of contention, the differences in beliefs, desires and values which motivate them, and the level at which the disagreements occur.

An interesting feature to emerge from the reconstruction was the layered nature of the process: instrumental arguments about the world provide premises for arguments about the application of legal concepts, which in turn form the basis for the resolution of the legal questions relating to the case. These levels constantly appear in work on case-based reasoning in AI and Law. We explored this concept in further detail. We took as an initial starting point the distinction made by Lindahl, Ashley, and others, between fact situations, intermediate legal concepts, and the consequences that flow from them, and related this distinction to the three levels of our reconstruction. We also followed Lindahl in distinguishing between different intermediate concepts according to how they are defined, whether by conditions intended to be sufficient to ascribe or withhold the concept, or by conditions which must be considered, although never individually necessary or sufficient. We further illustrated this by a detailed consideration of Sickness Benefit as an example 
of the former and a brief consideration of Trade Secrets as an example of the latter.

We believe that this discussion of the different levels of reasoning establishes a model which can be used to reconstruct legal reasoning about cases, and can explain different conclusions in the light of different beliefs and goals. The underlying argumentation can be generated by agents representing the different viewpoints, as described in our reconstruction of Pierson v. Post.

One important issue not resolved by this model is when (and why) agents choose to descend to Level 1, to argue for a change in the law. Dissent often results from one judge taking a legalistic view being opposed by another who takes an instrumental view. In other words, one reasons only at Level 2 while the other reasons at Level 1. It would be very helpful to have a better understanding of when this latter style of reasoning is appropriate.

\section{Acknowledgements}

Katie Atkinson is grateful for support from the EPSRC. Trevor Bench-Capon is grateful for partial support received from the European Commission, through Project ASPIC (IST-FP6-002307). We would also like to thank Peter McBurney for his contributions to our work on argumentation in practical reasoning and also for many fruitful conversations on the topic. This paper is an extension of one presented at the ICAIL 2005 workshop on Argumentation in AI and Law. We are grateful to audience of the workshop and to the anonymous reviewers for their helpful comments and suggestions.

\section{Notes}

1 We use the law as it was until 1995 since this is what was used in previous AI and Law work.

2 We use the term plan library here as used in a system such as the procedural reasoning system (PRS) (Georgeff and Lansky 1987). Alternatively, we note that the agent might derive its plans by reasoning in the specific context.

3 The text of this decision is available on a number of websites e.g. http://www.saucyintruder.org/pages/pierson.html.

4 Where no value is given, the argument is a statement of fact, and so can be taken as having "truth" as its value. In our approach, and following Bench-Capon (2003a), "truth" is the most highly ranked value for all audiences.

5 Adjudications on Social Security claims were initially given by a lay Adjudication Officer. Appeal was first to a lay tribunal of three persons, and then to a legally qualified Commissioner. Commissioners were able to select their decisions for report, and these decisions would then be binding on tribunals and Adjudication Officers. In the case of conflict among Commissioners, a Tribunal of three Commissioners would be convened to decide the issue, the decision of a Tribunal of Commissioners being binding on Commissioners. Reported decisions were communicated to Adjudication Officers through 
guidance setting out the consequences of the decision issued by the Office of the Chief Adjudication Officer. Thus at the Adjudicating Officer stage, decisions were made by applying the rules found in this guidance rather than independent interpretation of the decisions themselves.

6 Decisions are numbered according to the following convention. "R" stands for "reported" and the letter in brackets indicates the benefit concerned: "S" for "sickness", "U" for "unemployment" and so on. The first number indicates that the decision was the $n$th reported in the year, which follows the slash. Thus this decision is a reported decision concerning Sickness Benefit, and was the third decision of 1952.

7 We omit S, the circumstances resulting from the performance of the action since G represents the relevant subset of these circumstances. $\mathrm{S}$ is of importance only if we need to distinguish what results from an action, from the desires that it satisfies.

\section{References}

Aleven, V. (1997). Teaching Case Based Argumentation Through an Example and Models. PhD thesis, University of Pittsburgh, Pittsburgh, PA, USA.

Ashley, K. D. (1990). Modeling Legal Argument. MIT Press: Cambridge, MA, USA.

Ashley, K. D. and Brüninghaus, S. (2003). A Predictive Role for Intermediate Legal Concepts: In Bourcier, D. (ed.), Proceedings of the Sixteenth Annual Conference on Legal Knowledge and Information Systems (Jurix 2003), 153-162. IOS Press: Amsterdam, The Netherlands.

Atkinson K., Bench-Capon, T. and McBurney, P. (2004a). Attacks on a Presumptive Argument Scheme in Multi-Agent Systems: Pre-Conditions in Terms of Beliefs and Desires. Technical Report ULCS-04-015, Department of Computer Science, University of Liverpool, UK.

Atkinson, K., Bench-Capon, T. and McBurney P. (2004b). Justifying Practical Reasoning. In Grasso, F., Reed, C., and Carenini, G. (eds.), Proceedings of the Fourth International Workshop on Computational Models of Natural Argument (CMNA 2004), 87-90. Valencia, Spain.

Atkinson, K., Bench-Capon, T. and McBurney, P. (2005a). Persuasive Political Argument. In Grasso, F., Reed, C. and Kibble, R. (eds.), Proceedings of the Fifth International Workshop on Computational Models of Natural Argument (CMNA 2005), 44-51, Edinburgh, Scotland.

Atkinson, K., Bench-Capon, T. and Modgil, S. (2005b). Value Added: Processing Information with Argumentation. Technical Report ULCS-05-004, Department of Computer Science, University of Liverpool, UK.

Bench-Capon, T. (1989). Deep Models, Normative Reasoning and Legal Expert Systems. In Proceedings of the Second International Conference on AI and Law (ICAIL 1989), 37-45. ACM Press: New York, USA.

Bench-Capon, T. (1991a). Knowledge Based Systems Applied to Law: A Framework for Discussion. Knowledge Based Systems and Legal Applications: 329-342.

Bench-Capon, T. (1991b). Practical Legal Expert Systems: The Relation Between a Formalisation of Law and Expert Knowledge, 191-201. Ablex.

Bench-Capon, T. (2002a). Representation of Case Law as an Argumentation Framework. In Bench-Capon, T., Daskalopoulu, A. and Winkels, R. (eds.), Proceedings of the Fifteenth Annual Conference on Legal Knowledge and Information Systems (Jurix 2002), 103-112. IOS Press: Amsterdam. 
Bench-Capon, T. (2002b). The Missing Link Revisited: The Role of Teleology in Representing Legal Argument, Artificial Intelligence and Law 10(1-3): 79-94.

Bench-Capon, T. (2003a). Persuasion in Practical Argument Using Value Based Argumentation Frameworks, Journal of Logic and Computation 13(3): 429-48.

Bench-Capon, T. (2003b). Try to See it My Way: Modelling Persuasion in Legal Discourse, Artificial Intelligence and Law 11(4): 271-287.

Bench-Capon, T. and Rissland, E. (2001). Back to the Future: Dimensions Revisited: In Verheij, B., Lodder, A., Loui, R. and Muntjewerff, A. (eds.), Proceedings of the Fourteenth Annual Conference on Legal Knowledge and Information Systems (Jurix 2001), 41-52. IOS Press: Amsterdman, The Netherlands.

Bench-Capon, T. and Sartor, G. (2003). A Model of Legal Reasoning with Cases Incorporating Theories and Values, Artificial Intelligence 150(1-2): 97-143.

Bench-Capon, T. and Stainford, G. (1995) PLAID: Proactive Legal Assistance. In Proceedings of the Fifth International Conference on AI and Law (ICAIL 1995), 81-88. ACM Press: New York, NY, USA.

Berman, D. H. and Hafner, C. D. (1993). Representing Teleological Structure in Case-Based Legal Reasoning: The Missing Link. In Proceedings of the Fourth International Conference on AI and Law (ICAIL 1993), 50-59. ACM Press: New York, NY, USA.

Branting, K. L. (2003). An Agenda for Empirical Research in AI and Law. In Working Papers of the ICAIL'03 Workshop on Evaluation of Legal Reasoning and Problem-Solving Systems, 28-35. Edinburgh, UK.

Breuker, J. and den Haan, N. (1991). Separating World and Regulation Knowledge, Where is the Logic? In Proceedings of the Tenth International Conference on Artificial Intelligence and Law (ICAIL 1991), 92-97. ACM Press: New York, USA.

Brüninghaus, S. and Ashley, K. D. (2003) Predicting Outcomes of Case-Based Legal Arguments. In Proceedings of the Ninth International Conference on AI and Law (ICAIL 2003), 233-242. ACM Press: New York, NY, USA.

Dung, P. M. (1995). On the Acceptability of Arguments and its Fundamental Role in Nonmono-tonic Reasoning, Logic Programming and n-Person Games, Artificial Intelligence 77, 321-357.

Gardner, A. (1987). An Artificial Intelligence Approach to Legal Reasoning.

Georgeff, M. P. and Lansky, A. L. (1987). Reactive Reasoning and Planning. In Proceedings of the Sixth International Conference on Artificial Intelligence (AAAI-87), 677-682. Seattle, WA.

Greenwood, K., Bench-Capon, T. and McBurney, P. (2003). Towards a Computational Account of Persuasion in Law. In Proceedings of the Ninth International Conference on AI and Law (ICAIL 2003), 22-31. ACM Press: New York, NY, USA.

Hart, H. L. A. (1961). The Concept of Law. Oxford University Press: Oxford.

Lindahl, L. (2004). Deduction and Justification in the Law the Role of Legal Terms and Concepts, Ratio Juris Ratio Juris 17(2): 182-202.

Lindahl, L. and Odelstad, J. (2004). Normative Positions within an Algebraic Approach to Normative Systems. Journal of Applied Logic 17(2): 2005 To appear.

Lutomski, L. S. (1989). The Design of an Attorney's Statistical Consultant. In Proceedings of the Second International Conference on AI and Law (ICAIL 1989), 224-233. ACM Press: New York, NY, USA.

Marshall, C. C. (1989). Representing the Structure of a Legal Argument. In Proceedings of the Second International Conference on AI and Law (ICAIL 1989), 121-127. ACM Press: New York, NY, USA. 
McCarty, L. T. (1995). An Implementation of Eisner v Macomber. In Proceedings of the Fifth International Conference on AI and Law (ICAIL 1995), 276-286. ACM Press: New York, NY, USA.

McCarty, L. T. and Sridharan, M. S. (1982). A Computational Theory of Legal Argument. Technical Report LRP-TR-13, Computer Science Department, Rutgers University.

Neligan, D. (1979). Social Security Case Law: Digest of Commissioner's Decisions. HMSO: London.

Prakken, H. (2002). An Exercise in Formalising Teleological Case-Based Reasoning, Artificial Intelligence and Law 10(1-3): 113-133.

Prakken, H., Reed, C. and Walton, D. (2003). Argumentation Schemes and Generalizations in Reasoning About Evidence. In Proceedings of the Ninth International Conference on AI and Law (ICAIL 2003), 32-41. ACM Press: New York, NY, USA.

Prakken, H. and Sartor, G. (1996). A Dialectical Model of Assessing Conflicting Arguments in Legal Reasoning, Artificial Intelligence and Law 4(3-4): 331-368.

Ross, A. (1951). Tu-tu. In Borum, O. and Illum, K. (eds.), Festskrift til Henry Ussing. Kobenhavn Juristforbundet.

Sartor, G. (2002). Teleological Arguments and Theory Based Dialectics, Artificial Intelligence and Law 10(1-3): 95-112.

Toulmin, S. (1958). The Uses of Argument. Cambridge University Press: Cambridge, UK.

Trollope, A. (1986). The American Senator. Oxford University Press: Oxford, UK.

Valente, A. (1995). Legal Knowledge Engineering: A Modelling Approach. IOS Press: Amsterdam.

Verheij, B. (2003). Dialectical Argumentation with Argumentation Schemes: An Approach to Legal Logic, Artificial Intelligence and Law 11(2-3): 167-195.

Walton, D. N. (1996). Argument Schemes for Presumptive Reasoning. Lawrence Erlbaum Associates: Mahwah, NJ, USA.

Wooldridge, M. J. (2000). Reasoning About Rational Agents. MIT Press: Cambridge, MA, USA. 